\title{
CYCLIC DEFORMATION OF HAYNES 188 SUPERALLOY UNDER ISOTHERMAL AND THERMOMECHANICAL LOADINGS
}

\author{
Michael G. Castelli' and K. Bhanu Sankara Rao' \\ ${ }^{1}$ NYMA, Inc., ${ }^{2}$ National Research Council \\ National Aeronautics and Space Administration \\ Lewis Research Center \\ Cleveland, Ohio 44135
}

\section{Abstract}

A detailed assessment of the macroscopic and microstructural cyclic deformation behavior of Haynes $188^{\text {th }}$ has been conducted under various isothermal and thermomechanical conditions over the temperature range 25 to $1000^{\circ} \mathrm{C}$. A fully reversed mechanical strain range of $0.8 \%$ was examined with constant mechanical strain rates of $10^{-3} \mathrm{~s}^{-1}$ and $10^{-4} \mathrm{~s}^{-1}$. Particular attention was given to the effects of dynamic strain aging (DSA) on the stress-strain response. Detailed transmission electron microscopy was conducted to examine the deformation substructures and establish correlations with the cyclic macroscopic behaviors. Although DSA was found to occur over a wide temperature range between approximately 300 and $700^{\circ} \mathrm{C}$, the microstructural characteristics and deformation mechanisms responsible for DSA varied considerably and were dependent upon temperature. In general, the operation of DSA processes led to a maximum of the cyclic stress amplitude at $\sim 650^{\circ} \mathrm{C}$, and was accompanied by pronounced planar slip, the generation of stacking faults and high dislocation density. DSA was evidenced through a combination of phenomena, including serrated yielding, an inverse dependence of maximum cyclic hardening with strain rate $(\varepsilon)$, and an instantaneous inverse $\varepsilon$ sensitivity. The TMF cyclic hardening behavior exhibited unique behaviors in comparison to the isothermal response, predominantly at the minimum TMF temperature extremes.

\section{Introduction}

The cobalt base superalloy, Haynes $188^{\mathrm{mm}}$, is currently used in many aeronautics and aerospace applications, including extensive use in military and commercial aircraft turbine engines as a combustor liner material. The choice for use of this material is primarily based upon a good combination of its monotonic yield and tensile strength properties, excellent fabricability, weldability and good resistance to high temperature oxidation for prolonged exposures [1]. In the vast majority of aero applications, the various components are subject to repeated thermal and mechanical loadings, thus, making high temperature cyclic deformation and failure a primary concern for long term structural integrity and component life. Initial examinations of the high temperature cyclic behavior of Haynes $188^{\mathrm{Tw}}$ revealed relatively complex behaviors. Various combinations of temperature, strain, and strain rate exert a strong influence on the cyclic stress response through the interaction of various time- and temperature-dependent phenomena, such as inelastic flow, dynamic strain ageing (DSA), creep and environmental damage, and dynamic precipitation.

$$
\text { Superalloys } 1996
$$

Thus, with the ultimate goal of accurately modeling and predicting such behaviors, it is critical to have a comprehensive understanding of both the macroscopic cyclic deformation behavior under general thermomechanical loading conditions, and the micromechanisms which influence such behaviors, as revealed in the deformation substructure. Further, this understanding must include not only material behaviors at maximum operating temperatures, but also the behaviors at the lower temperatures encountered during transients.

Several past efforts aimed at characterizing the effects of temperature and mechanical loads on the fatigue behavior of Haynes $188^{\mathrm{T}}$ have generally been focused upon relatively select conditions. These include elevated temperature stress-free exposures [2], the influence of temperature and creep-fatigue interaction on strain-life relationships [3], and the examination of thermomechanical and bithermal fatigue behavior and damage modes for developing suitable methods for life prediction [4-6]. Additionally, loading frequency effects on crack growth behavior [7] and the effects of axial/torsional loading on cyclic deformation [8] have been examined. With these efforts, however, the cyclic stress response and fatigue lives over a wide temperature range have not been examined in depth; and further, there is little to no information available on the dislocation arrangements and deformation induced microstructures of Haynes $188^{\mathrm{TW}}$ during elevated temperature fatigue loadings.

Toward the end of characterizing both the macro and substructural deformation behaviors during high temperature fatigue loadings, a series of isothermal fatigue, and in-phase and out-of-phase thermomechanical fatigue (TMF) tests were conducted in the range 25 to $1000^{\circ} \mathrm{C}$ at multiple strain rates on Haynes $188^{\mathrm{T*}}$. As the thermal stresses within a component are often highly localized and deformation constrained by surrounding material (i.e., deformation controlled), strain controlled loadings were examined using a fully reversed mechanical strain range of $0.8 \%$. Detailed examinations of the deformation substructures were performed leading to a correlation between the micro and macro phenomenological cyclic deformation behaviors. Particular attention was given to the effects of dynamic strain aging (DSA) on the stress-strain response. The temperature dependence of the TMF deformation behavior is examined over several temperature intervals and compared with those observed under isothermal conditions. Macroscopic hardening behaviors unique to the TMF conditions are discussed and interpreted in accord with the isothermal deformation substructures. 


\section{Material and Experimental Detaile}

The Haynes Alloy $188^{*}$ was originally supplied as hot rolled and solution annealed bar of $19 \mathrm{~mm}$ dia. Solution annealing was carried out at $1175^{\circ} \mathrm{C}$ for $1 \mathrm{hr}$ followed by water quenching. which produced an average grain size of ASTM 6 in the longitudinal direction. The material had the chemical composition (wt\%) of $22.43 \mathrm{Ni}, 21.84 \mathrm{Cr}, 13.95 \mathrm{~W}, 1.24 \mathrm{Fe}, 0.01 \mathrm{C}$, $0.75 \mathrm{Mn}, 0.40 \mathrm{Si}, 0.012 \mathrm{P}, 0.002 \mathrm{~S}, 0.034 \mathrm{La}, 0.002 \mathrm{~B}$ with the balance being $\mathrm{Co}$.

Fully-reversed, total axial strain controlled isothermal LCF tests were performed on $6 \mathrm{~mm}$ dia. and $12.5 \mathrm{~mm}$ parallel gage length specimens at different temperatures in the range 25 to $1000^{\circ} \mathrm{C}$, employing a triangular waveform and an axial strain range $(\Delta \varepsilon)$ of $0.80 \%$. The strain rates ( $\varepsilon)$ applied in the isothermal testa included $10^{-4} 8^{-1}$ and $10^{-3} 8^{-1}$. In-phase (IP) and out-of-phase (OP) TMF tests with a mechanical $\hat{\varepsilon}$ of $10^{-4} \mathrm{~g}^{-1}$ were conducted on parallel sided tubular specimens featuring a 8.4 and $11.4 \mathrm{~mm}$ inner and outer dia, respectively, and a longitudinal gage length of $12.7 \mathrm{~mm}$. Here, IP loading were defined as the condition where maximum tensile strain coincided with the maximum temperature, and the maximum compressive strain with the minimum temperature; whereas, under OP conditions the maximum tensile strain coincided with the minimum temperature, and the maximum compressive strain coincided with the maximum temperature. In the TMF tests, the control of total axial strain was accomplished by continuously providing for compensation of the thermal strain, such that the mechanical strain range $\left(\Delta \varepsilon^{m}\right)$ was $0.80 \%$.

Strains were measured with a high temperature water-cooled extensometer. All test specimens were heated with direct induction heating and cooling was accomplished through the use of water cooled grips; no forced air was used. Temperature gradiente over the gage section were maintained within $\pm 1 \%$ of the nominal test temperature for the isothermal testa and $\pm 1.5 \%$ of the nominal dynamic test temperature for the TMF testa. The temperature was monitored and controlled with K-type thermocouplea spot welded on the specimen surface. Cracks were not found to preferentially initiate at the spot weld locations during testing.

In general, a minimum of four specimens were tested at each of the isothermal temperatures. For a given set of conditions, duplicate teats showed very similar hysteresis behavior and the extent of variation in cyclic strese hardening/softening was relatively small. For the sake of brevity, the results reported here are limited to data from single specimens tested at each temperature. The TMF teste consisted of only single tests for each condition.

Microstructural examinations were conducted on failed specimens to document the microstructural changes that occurred during testing. Energy dispersive analysis of X-rays $(\mathrm{EDAX})$ and the determination of lattice parameters by $\mathrm{X}$-rays, were used to identify various precipitates. Deformation induced substructures were studied by transmission electron microscopy (TEM). Samples for TEM examination were obtained from thin slices cut at a distance of $1 \mathrm{~mm}$ away from the fracture surface. The slices were mechanically thinned down to $250 \mathrm{\mu m}$, and then electropolished in a solution containing $10 \%$ perchloric acid and $90 \%$ methanol, at $22 \mathrm{~V}$ and $5^{\circ} \mathrm{C}$, in a twin jet apparatus. Thin foils were examined in an electron microscope operating at an acceleration voltage of $120 \mathrm{keV}$.
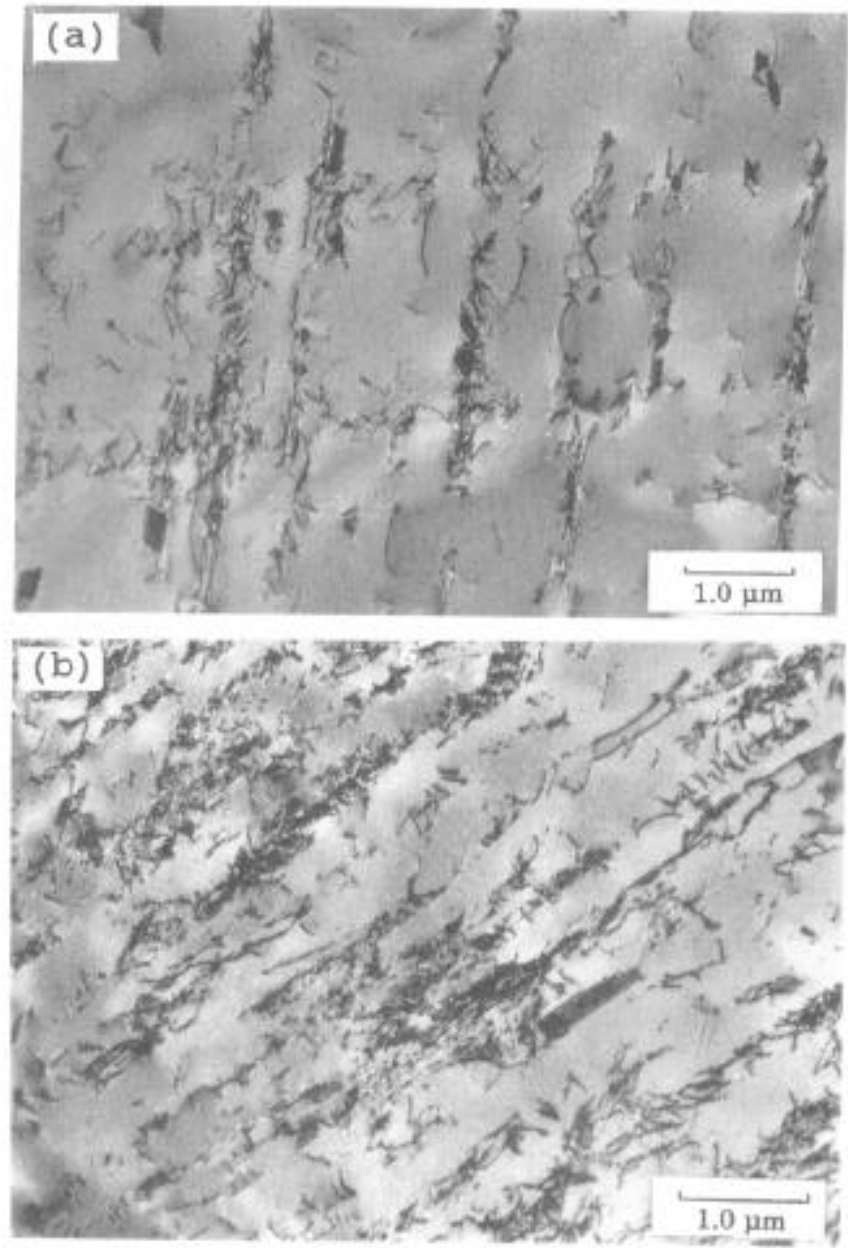

Figure 1: Representative TEM micrographs depicting (a) dislocation dipoles and bundles in two slip planes at $25^{\circ} \mathrm{C}$ and (b) planar slip bands exhibiting loops, dipoles and stacking faults at $300^{\circ} \mathrm{C}$.

\section{Results and Discussion}

The primary focus of the research was to examine and characterize both the substructural and macroscopic deformation behaviors under high temperature fatigue loadings, and with this, to establish a correlation between the two. Therefore, the discussion will begin by examining the microstructure in the as-received condition and those developed as a result of the isothermal fatigue loadings. Subsequently, the macroscopic isothermal and TMF deformation behaviors will be described and discussed in view of the features detailed in the deformation substructures.

\section{Isothermally Developed Deformation Subatructures}

In the as-received condition (solution annealed state), the Haynes $188^{\prime \prime}$ alloy contained randomly distributed undissolved blocky particles identified as tungsten rich $\mathrm{M}_{\mathrm{n}} \mathrm{C}$ through energy dispersive $\mathrm{X}$-ray and X-ray diffraction analyses [9]. It is apparent that these precipitates nucleated in the melt and were not dissolved during the solution treatment. These bulk precipitates will be referred to hereafter as primary $\mathrm{M}_{8} \mathrm{C}$

Microstructures developed during isothermal fatigue at 25 and $300^{\circ} \mathrm{C}$ with $\hat{t}=10^{-3} \mathrm{~s}^{-1}$ are shown in Fig. Ia and $1 \mathrm{~b}$, respectively. 

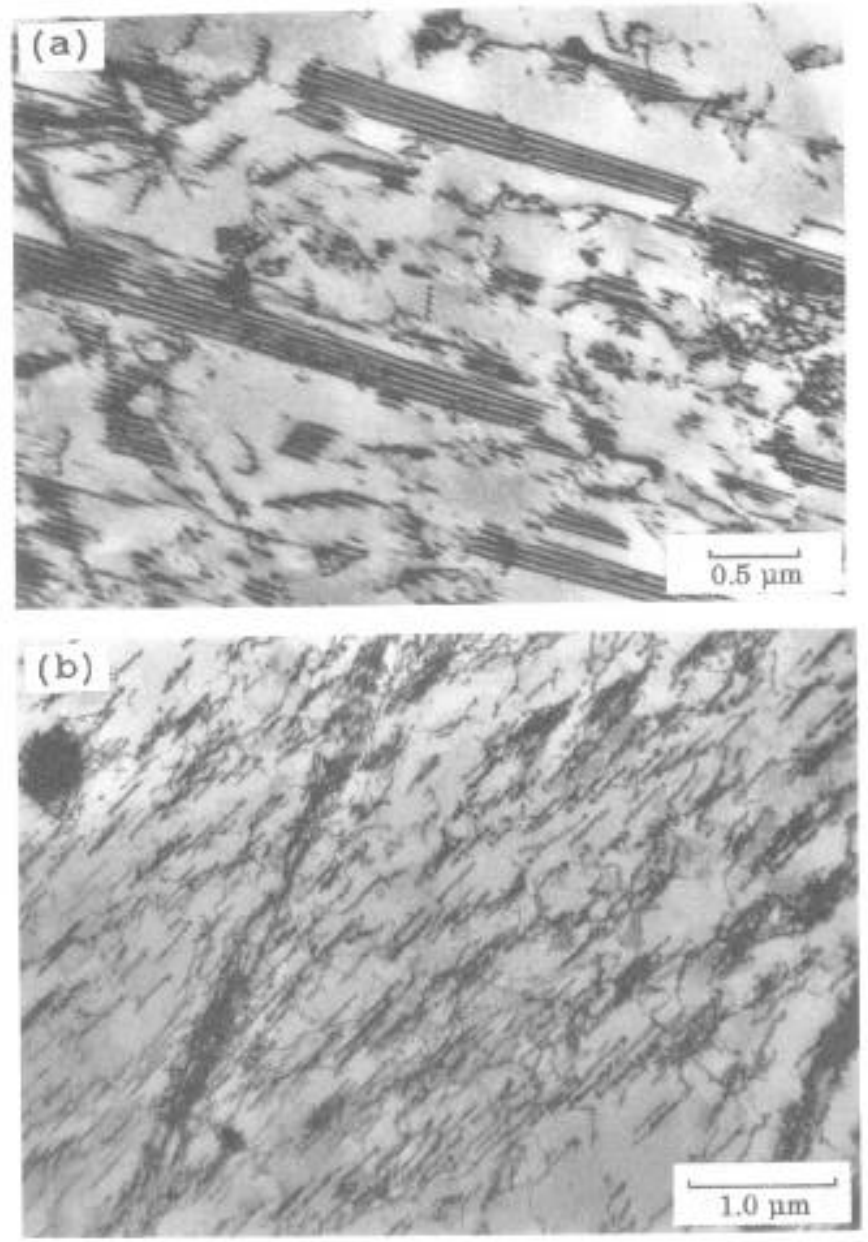

Figure 2: Representative TEM micrographs exhibiting the predominant staking faults and planar slip generated under (a) $400^{\circ} \mathrm{C}$, and (b) $550^{\circ} \mathrm{C}$ isothermal fatigue conditions.

The features revealed in this figure are representative of those which developed over the general temperature range from 25 to $300^{\circ} \mathrm{C}$. Based upon the macroscopic deformation data to be discussed, this temperature range represents a regime below the DSA domain, that is, the low temperature regime in which DSA effects appeared not to be active. In this temperature regime, deformation substructures were generally made up of distinctly spaced slip bands incorporating dislocation bundles and dipoles, and tangles at the intersection of multiple slip bands such as illustrated in Fig. 1a. As illustrated in Figs. 1a and b, planar slip occurred with the simultaneous operation of two slip systems. With increasing temperature in this range, a relative increase in dislocation density within the slip banda was evident. Thus, the substructure resulting from fatigue cycling at $300^{\circ} \mathrm{C}$ exhibited intense slip bands in which dislocation debris in the form of loops, dipoles and stacking faults accumulated, as illustrated in Fig. 1b. Here, it was often difficult to distinguish individual dislocations in the slip bands because of extensive tangling. Although dislocations were generated in two slip systems, the density of one system in a given grain was usually higher than that of the other, probably due to the difference between shear stresses of different slip systems. In this temperature regime, no significant differences were evident between the microstructures generated under $\hat{\varepsilon}=10^{-4} g^{-1}$ and $\varepsilon=10$ $4 s^{-1}$ isothermal fatigue conditions.

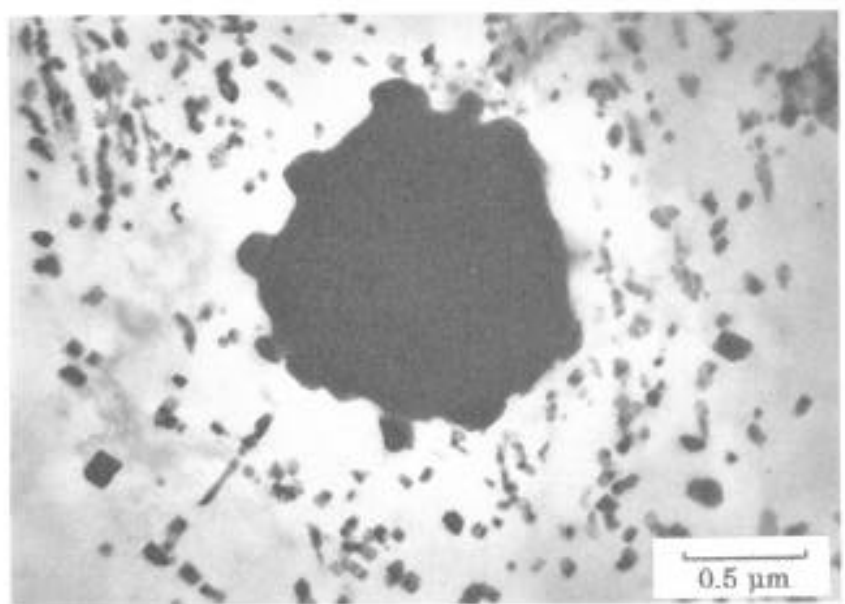

Figure 3: TEM micrograph depicting very fine $\mathrm{M}_{23} \mathrm{C}_{6}$ precipitated about the larger primary $\mathrm{M}_{6} \mathrm{C}$ at $750^{\circ} \mathrm{C}$.

The second temperature domain discussed is the general regime where DSA effects were evidenced in the macroscopic deformation response, that is approximately 350 to $700^{\circ} \mathrm{C}$. DSA has been proposed to occur due to the aging of mobile dislocations by solute atmo日pheres either during a quasiviscous type of motion of dislocations or when the dislocations are temporarily held up at local obstacles in the glide plane. When DSA operates, in order to maintain the imposed strain amplitude, additional dislocations are generated, leading to observed increases in dislocation densitien. In the low to mid temperatures of the DSA domain (i.e., -350 to $550^{\circ} \mathrm{C}$ ), dislocations frequently formed planar arrays, extensive pile-ups at grain boundaries, and developed numerous stacking faults. These features are represented by the deformation substructures shown in Figs. 2a and $2 \mathrm{~b}$ taken from isothermal fatigue specimens tested at 400 and $550^{\circ} \mathrm{C}$, respectively, with $\varepsilon=10^{-3} \mathrm{~s}^{-1}$. In general, the planar slip and stacking faults were developed over the entire range from 25 to $-700^{\circ} \mathrm{C}$; however, the propensity for their occurrence appeared to reach a peak in the range of 400 to $550^{\circ} \mathrm{C}$. The origin of the planar slip in the DSA regime is believed to result from the combined effects of the elastic interaction between the solute atoms and the dislocations, and the Suzuki segregation on stacking faults [10]. Towards the end of the DSA regime at 600 and $650^{\circ} \mathrm{C}$, dislocations aseumed a configuration of well knit networks with densities exhibiting a maximum, in comparison to those developed at all other isothermal test temperatures. At $650^{\circ} \mathrm{C}$ (in a majority of the grains) the deformation was more homogeneous and the predominant coplanar slip was not apparent. As similar to the low temperature regime, no significant differences were evident between the microstructures generated under $\varepsilon=10^{-3} \mathrm{~s}^{-1}$ and $\varepsilon=10^{-4} \mathrm{~s}^{-1}$ conditions.

The final temperature regime, designated as the high temperature domain, consisted of those temperatures ranging from approximately 750 to $1000^{\circ} \mathrm{C}$. In the isothermal fatigue teats at $750^{\circ} \mathrm{C}$, precipitation of a chromium rich $\mathrm{M}_{28} \mathrm{C}_{6}$ carbide occurred. Substantial numbers of these very fine $\mathrm{M}_{29} \mathrm{C}_{5}$ could be seen intragranularly precipitated around the larger primary $\mathrm{M}_{6} \mathrm{C}$ as shown in Fig. 3 . The $\mathrm{M}_{28} \mathrm{C}_{6}$ served to pin deformation induced dislocations and generally led to an inhomogeneous distribution of dislocations (predominantly at $\mathrm{M}_{29} \mathrm{C}_{6}$ sites), as illustrated in Fig. 4. This pinning effect was considerably reduced with increasing temperature to $850^{\circ} \mathrm{C}$ where the 


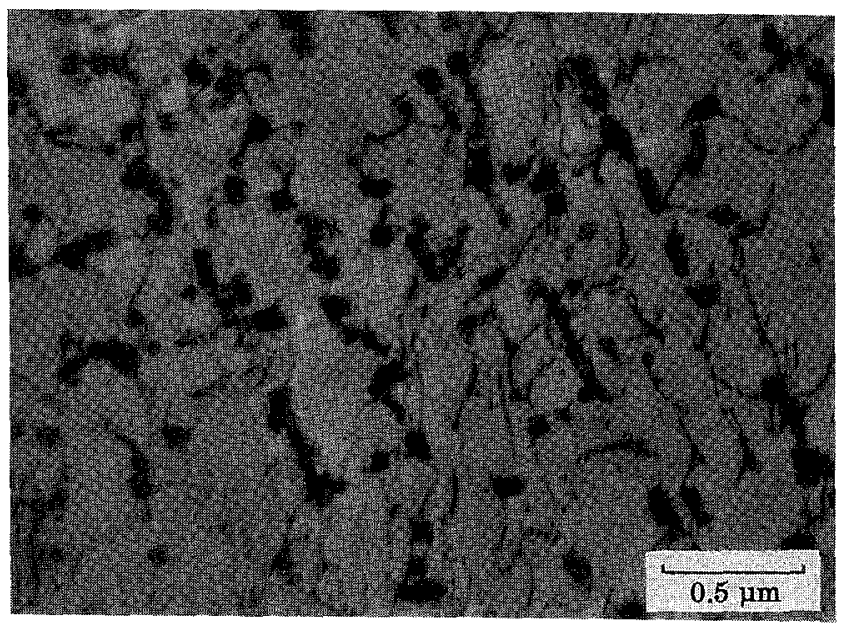

Figure 4: TEM micrograph revealing $\mathrm{M}_{28} \mathrm{C}_{8}$ dislocation pinning effect at $750^{\circ} \mathrm{C}$.

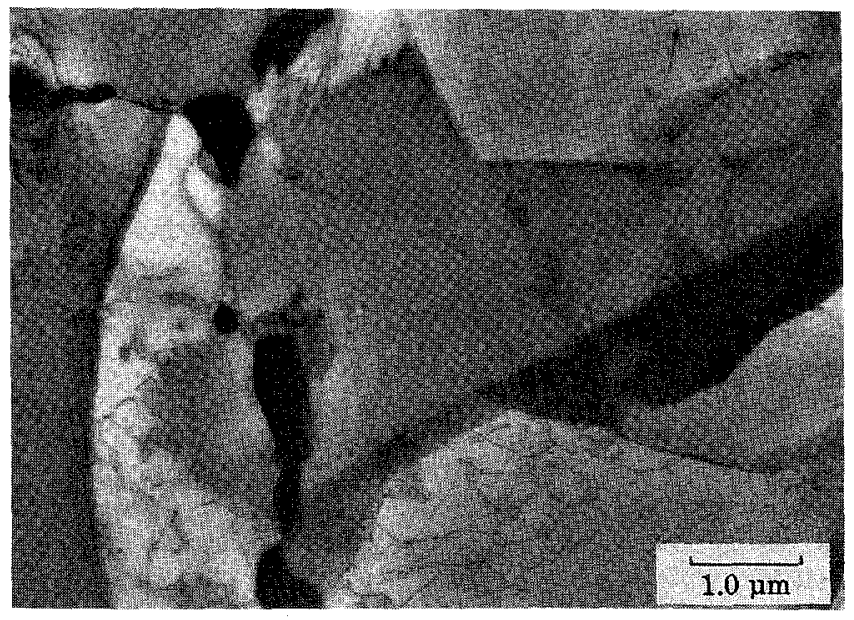

Figure 5: TEM micrograph revealing secondary procipitation of $\mathrm{M}_{6} \mathrm{C}$ on grain boundaries at $1000^{\circ} \mathrm{C}$.

dislocations appeared much more uniformly distributed. At temperatures higher than $850^{\circ} \mathrm{C}$, dynamic recovery by thermally activated dislocation climb gained importance leading to the formation of cells and subgrains with sharp walls. Above $900^{\circ} \mathrm{C}$, $\mathrm{M}_{6} \mathrm{C}$ was found to be the predominant phase both in the intraand intergranular regions, as secondary $M_{6} C$ was found to precipitate as discrete particles on grain boundaries, shown in Fig. 5 from a specimen tested at $1000^{\circ} \mathrm{C}$ with $\varepsilon=10^{-3} \mathrm{~s}^{-1}$. At the extreme temperatures of this regime, the subgrain interiors became virtually free of dislocations with the subgrain walls generally displaying orderly arrangements of dislocations.

In this high temperature domain from approximately 750 to $1000^{\circ} \mathrm{C}$, modest differences could be noted between the microstructures resulting from cycling at the two different strain rates. Generally speaking, at the lower (i.e., $=10^{-4} \mathrm{~s}^{-1}$ ), the substructural features associated with thermal recovery effects, such as growth of the $\mathbf{M}_{23} \mathrm{C}_{6}$, a decrease in intragranular dislocation density, the formation of cells and subgrains and the secondary precipitation of $\mathrm{M}_{8} \mathrm{C}$ became apparent at slightly lower temperatures in comparison to the high $\varepsilon$ tests. This, most likely due to the significantly increased time at test temperature (a factor of 10).

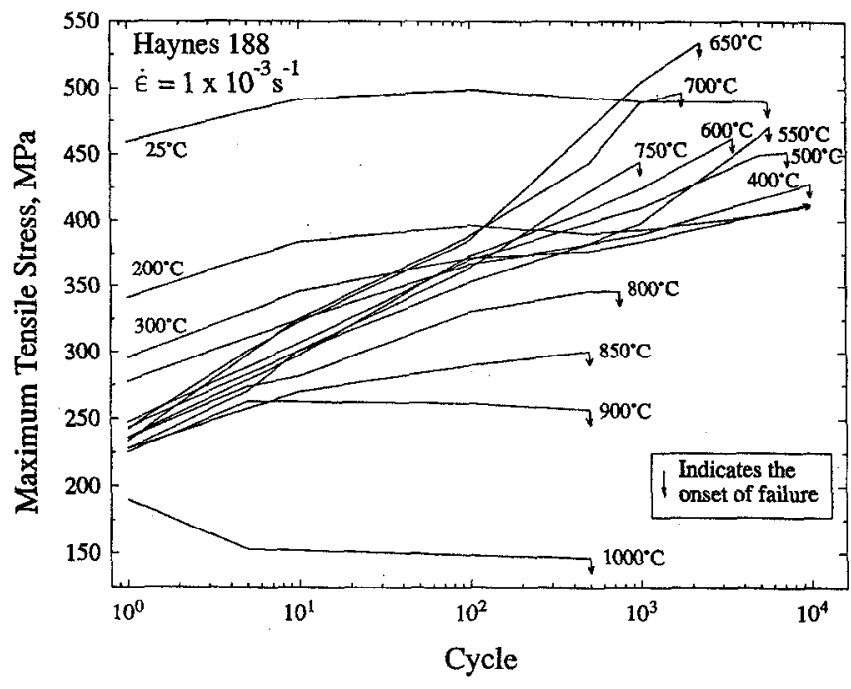

Figure 6: Cyclic maximum tensile stress during isothermal fatigue with $\Delta \varepsilon=0.8 \%$ and $\varepsilon=10^{-3} \mathrm{~s}^{-1}$.

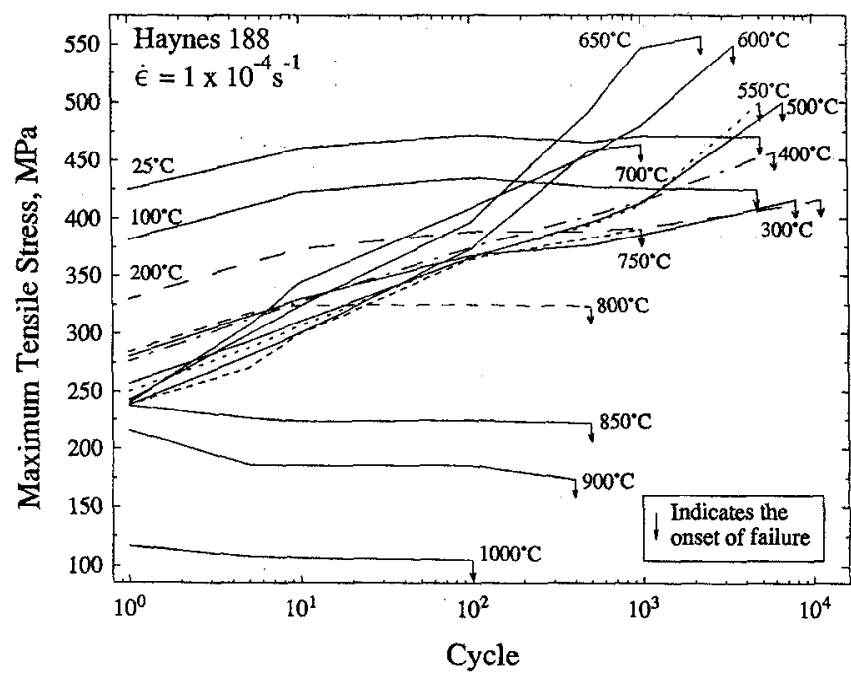

Figure 7: Cyclic maximum tensile stress during isothermal fatigue with $\Delta \varepsilon=0.8 \%$ and $\varepsilon=10^{-4} \mathrm{~s}^{-1}$.

\section{Macroscopic Deformation and Stress Response}

Isothermal Fatigue. The cyclic stress responses exhibited during isothermal fatigue with $\varepsilon=10^{-3} \mathrm{~s}^{-1}$ and $\varepsilon=10^{-4} \mathrm{~s}^{-1}$ are shown in Figs. 6 and 7, respectively. The curves illustrate the temperature dependence of the cyclic peak tensile stress $\left(\sigma_{\operatorname{mon}}\right)$ as a function of progressive cycles for both strain rates. The downward arrows terminating the stress response curves represent the onset of failure of the specimen. That is, the point at which crack nucleation and growth impaired the loadcarrying capacity of the specimen. As in the discussion of the deformation substructures, the temperature dependent stress response will be considered in three general domains, these are low $\left(25\right.$ to $\left.-300^{\circ} \mathrm{C}\right)$ mid $\left(350\right.$ to $\left.-700^{\circ} \mathrm{C}\right)$ and high $\left(\mathrm{T} \geq 750^{\circ}\right)$, where the mid temperature regime represents the DSA domain. In the low temperature regime for both strain rates, the alloy exhibited a brief period of initial moderate hardening, followed by an extended period of essentially stable stress response which persisted until the onset of failure. In general, at both strain rates, $\sigma_{\max }$ decreased with increasing temperature to 


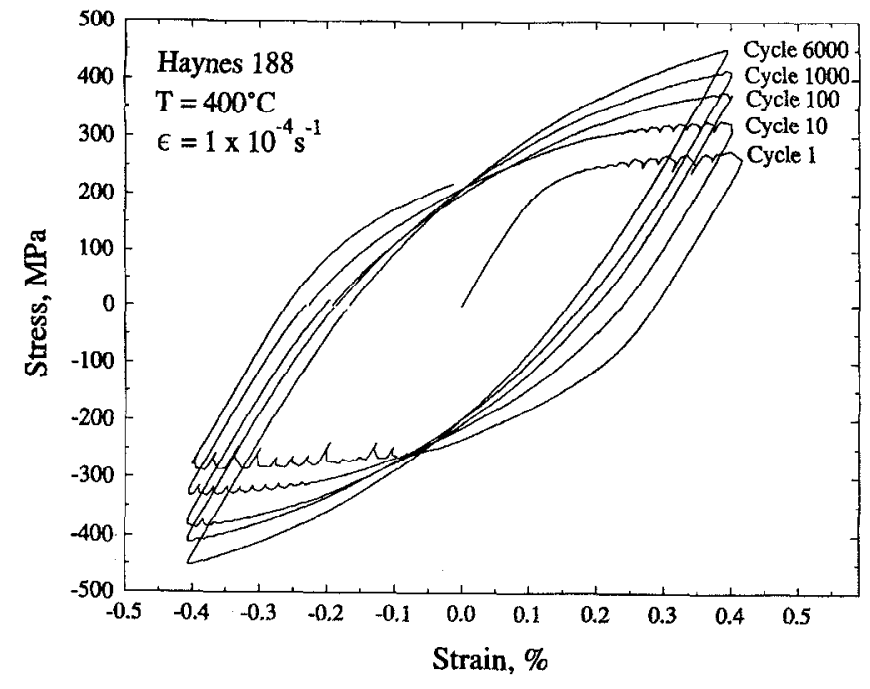

Figure 8: Progressive hysteresia loops illustrated serrated flow experienced in Haynes $188^{\mathrm{nx}}$.

$300^{\circ} \mathrm{C}$, consistent with the trend exhibited by the first-cycle stress. Thus, the cyclic hardening exhibited at approximately $300^{\circ} \mathrm{C}$ represents a local minimum which occurs just prior to the regime where DSA becomes active.

In the mid temperature domain $\left(350\right.$ to $\left.-700^{\circ} \mathrm{C}\right)$, which varied slightly depending on $\varepsilon$, continuous cyclic hardening generally occurred until the onset of failure. Here $\sigma_{\max }$ displayed an increase with increasing temperature to approximately $650^{\circ} \mathrm{C}$ where the most pronounced hardening behavior was observed. Also note that the number of cycles required to attain $\sigma_{\max }$ decreased with increasing temperature. Above $650^{\circ} \mathrm{C}$, the $\sigma_{\operatorname{mex}}$ exhibited a fall (relatively large in the $\varepsilon=10^{-4} \mathrm{~s}^{-1}$ tests) with increasing temperature. Calculations of the inelastic strain range developed in the cycle at half-life showed a rapid decrease with a raise in temperature in this range to $650^{\circ} \mathrm{C}$ at both strain rates. In tests performed at $\varepsilon=10^{-3} \mathrm{~s}^{-1}$, the deformation behavior displayed serrations in the plastic portions of stress-strain hysteresis loops between 300 and $850^{\circ} \mathrm{C}$, while at the lower serrated flow was observed over the much narrower range of $\mathbf{4 0 0}$ to $650^{\circ} \mathrm{C}$. This behavior is exemplified by the progressive hysteresis loops shown in Fig. 8 from a test conducted at $400^{\circ} \mathrm{C}$ with $\varepsilon=10^{-4} g^{-1}$. Here, serrated flow is experienced predominantly in the early cycles.

The occurrence of DSA was suggested by several observations, including $i)$ the maximum cyclic hardening occurred at an intermediate temperature, i.e., $650^{\circ} \mathrm{C}$, ii) the deformation behavior revealed serrated flow, and $i i i)$ both the $\sigma_{\max }$ and the inelastic strain at half-life showed an inverse temperature dependence with strain rate in the mid temperature domain. A comparison of $\sigma_{\max }$ values attained at identical temperatures in Figs. 6 \& 7 revealed an increase in $\sigma_{\max }$ with decreasing $\varepsilon$ between 400 and $700^{\circ} \mathrm{C}$, establishing the negative dependence of $\sigma_{\max }$ on $\varepsilon$. Note that above and below this temperature range, $\sigma_{\max }$ decreased with decreasing $\varepsilon$. The occurrence of a negative dependence of maximum stress on the $\varepsilon$ is a typical manifestation of fatigue deformation accompanying DSA [11-13].

In an effort to obtain further insight into the macroscopic aspects of DSA during isothermal fatigue, the instantaneous strain rate sensitivity (ISRS) of cyclic stress was also examined. The ISRS is to be distinguished from the strain rate sensitivity of $\sigma_{\max }$

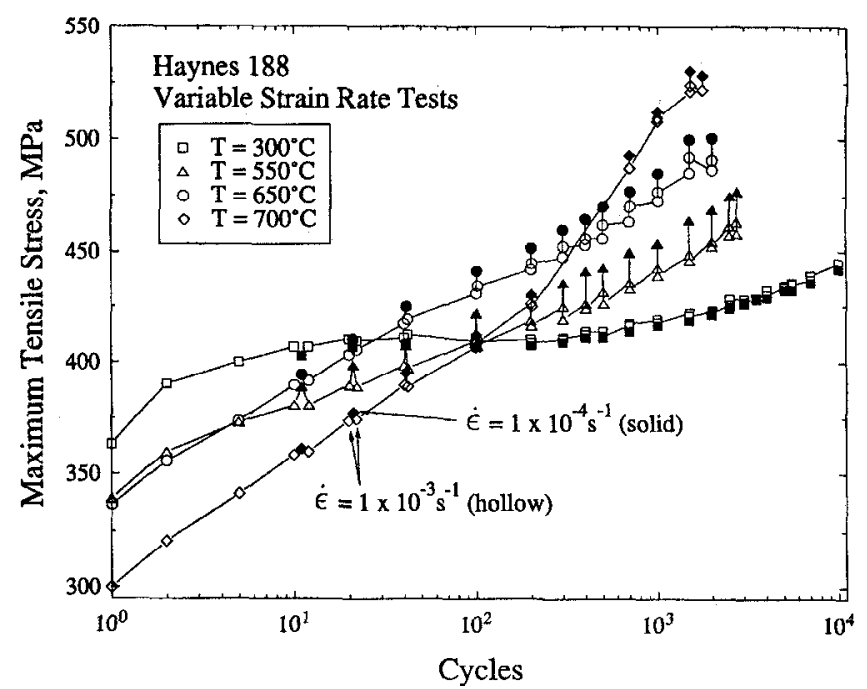

Figure 9: Cyclic stress response in the instantaneous strain rate sensitivity tests $\left(10^{-3}\right.$ to $\left.10^{-4} \mathrm{~s}^{-1}\right)$.

discussed above, as the ISRS corresponds to an immediate material response brought about by a sudden change in loading rate, with the condition that the substructure has not undergone any significant changes from one loading to the next. Whereas, the strain rate sensitivity of $\sigma_{\max }$ is related to the overall stress hardening as influenced by $\varepsilon$ under cyclic conditions. The ISRS was investigated by conducting instantaneous strain-rate-change tests at several temperatures; these tests were accomplished by conducting cyclic tests with a nominal $\varepsilon$ of $10^{-3} \mathrm{~s}^{-1}$ and periodically changing the $\varepsilon$ to $10^{-4} \mathrm{~s}$ for one cycle and then reverting to the faster rate. This "changeup" was implemented at periodic intervals throughout the test. Representative results from these tests are given in Fig. 9. The data indicated that the ISRS of the stress amplitude was positive at $300^{\circ} \mathrm{C}$, strongly negative at 550 and $650^{\circ} \mathrm{C}$ and only slightly negative at $700^{\circ} \mathrm{C}$. At $750^{\circ} \mathrm{C}$, the strain rate sensitivity was negative in the first 200 cycles, unaltered between 200 and 400 cycles and became positive above 400 cycles. The ISRS was positive above $750^{\circ} \mathrm{C}$. At 550 and $650^{\circ} \mathrm{C}$, when the strain rate was decreased to $10^{-4} \mathrm{~s}^{-1}$, the stress amplitude increased significantly and then returned to its regular progression upon increasing the strain rate to $10^{-8} \mathrm{~s}^{-1}$, indicating the change in stress amplitude is truly a reversible strain rate effect but not associated with a change in microstructure. The ISRS became progressively negative with increasing number of cycles in the range $400-700^{\circ} \mathrm{C}$. In conjunction with the observation of several other manifestations, the strain rate change test results suggest the operation of DSA between 400 to $750^{\circ} \mathrm{C}$. It is important to note, however, that the domain of serrated flow was much broader than that of the DSA, if the negative ISRS is considered as the compelling indicator of DSA.

The main features of dislocation substructure in the DSA range $\left(\sim 350\right.$ to $\left.700^{\circ} \mathrm{C}\right)$ were the pronounced occurrence of stacking faults and co-planar distribution of dislocations as shown in Fig. 2, and very high dislocation densities and very fine precipitation of carbides towards the maximum end of the temperature range. The microstructural origin of DSA effects has been studied in various stainless steels $[12,14,15]$. In these materials, the dislocation substructure changed from a so-called wavy slip mode to a predominantly planar slip mode in the temperature range of maximum DSA and became wavy again at higher temperatures. In the present study, the observation 
of multiple slip below $300^{\circ} \mathrm{C}$, the occurrence of co-planar slip bands with high dislocation density in the DSA range, and the cells and subgrains above the DSA range are all in qualitative agreement with the results reported on austenitic stainless steels. The abnormally high rates of cyclic hardening observed in the DSA regime could be associated with either the development of greater dislocation densities or precipitation of the $\mathrm{M}_{23} \mathrm{C}_{6}$ phase. The increase in the work hardening rate in the DSA regime has been attributed to the increased rate of accumulation of dislocations [13,15-17]. During DSA, due to aging of mobile dislocations by solute atmospheres, the material will continuously generate new dislocations in order to maintain the desired density of mobile dislocations at the imposed strain rate. Alternatively, $M_{28} C_{6}$ precipitation will hinder the dislocation movement of existing dislocations and enhance the production of additional dislocations to accommodate the applied strain. In fact, the interrupted cyclic deformation tests conducted on Hastelloy X by Miner and Castelli [16] showed a progressive and considerable increase in dislocation density over a greater number of cycles in the DSA range compared to that at room temperature. In Hastelloy $X$, the dislocation densities at failure also steadily increased on raising the temperature from 200 to $600^{\circ} \mathrm{C}$ in the DSA range.

In the present study, in the tests below $700^{\circ} \mathrm{C}$, carbide precipitation did not occur; therefore, the marked hardening experienced below this temperature, such as at 500,550,600, and $650^{\circ} \mathrm{C}$ can be attributed to the effects of DSA of dislocations by solute atoms $[12,13,15,18]$. At these temperatures, deformation enhanced diffusion of chromium has been considered to impede the motion of mobile dislocations and DSA leads to changes in dislocation density without precipitate formation. At 700 and $750^{\circ} \mathrm{C}$, the cyclic hardening appears to have been influenced by the combined effects of DSA and precipitation hardening. At dislocations, the chromium combines immediately with the rapidly diffusing carbon to form the carbides which provide the strong locking of dislocations. The carbides are very effective in pinning the dislocations when their size is extremely small. Rapid coarsening of the precipitates reduces the potential for the occurrence of DSA above $750^{\circ} \mathrm{C}$.

In the high temperature domain $\left(T \geq 750^{\circ} \mathrm{C}\right.$ ), a dramatic reduction in cyclic hardening was observed in comparison to that which occurred in the DSA domain. Tests conducted at $10^{-3} \mathrm{~s}^{-1}$ experienced moderate hardening (decreasing with increasing temperature) to $\sim 900^{\circ} \mathrm{C}$, above this point, cyclic softening became evident. At $10^{-4} \mathrm{~s}^{-1}$, this general trend was also exhibited; however, softening effects commenced at $850^{\circ} \mathrm{C}$. In the regime between 750 and $900^{\circ} \mathrm{C}$, microstructural observations indicated that in the high $\varepsilon$ tests a greater number of dislocations remained anchored by the $M_{23} C_{6}$ precipitates when compared to those in the low tests. Dislocation pinning by carbides appeared to impede thermal recovery in the higher $\varepsilon$ tests and led to modest cyclic hardening, albeit at a declining rate with increasing temperature. In general, the decreased dislocation densities and subgrain structures observed at the very high temperatures, such as those illustrated in Fig. 5, clearly suggest that the thermal recovery processes became dominant, and as a result, cyclic softening and a strong positive strain rate dependence was observed.

Thermomechanical Fatigue, The cyclic stress responses experienced under IP TMF conditions are shown in Fig. 10, where Fig. 10a contains data from the lower temperature conditions $\left(\triangle T: 350-550 \& 400-650^{\circ} \mathrm{C}\right.$ ), and Fig. $10 \mathrm{~b}$ contains data from the higher temperature conditions ( $\triangle T$ : 500-750 \& 600-
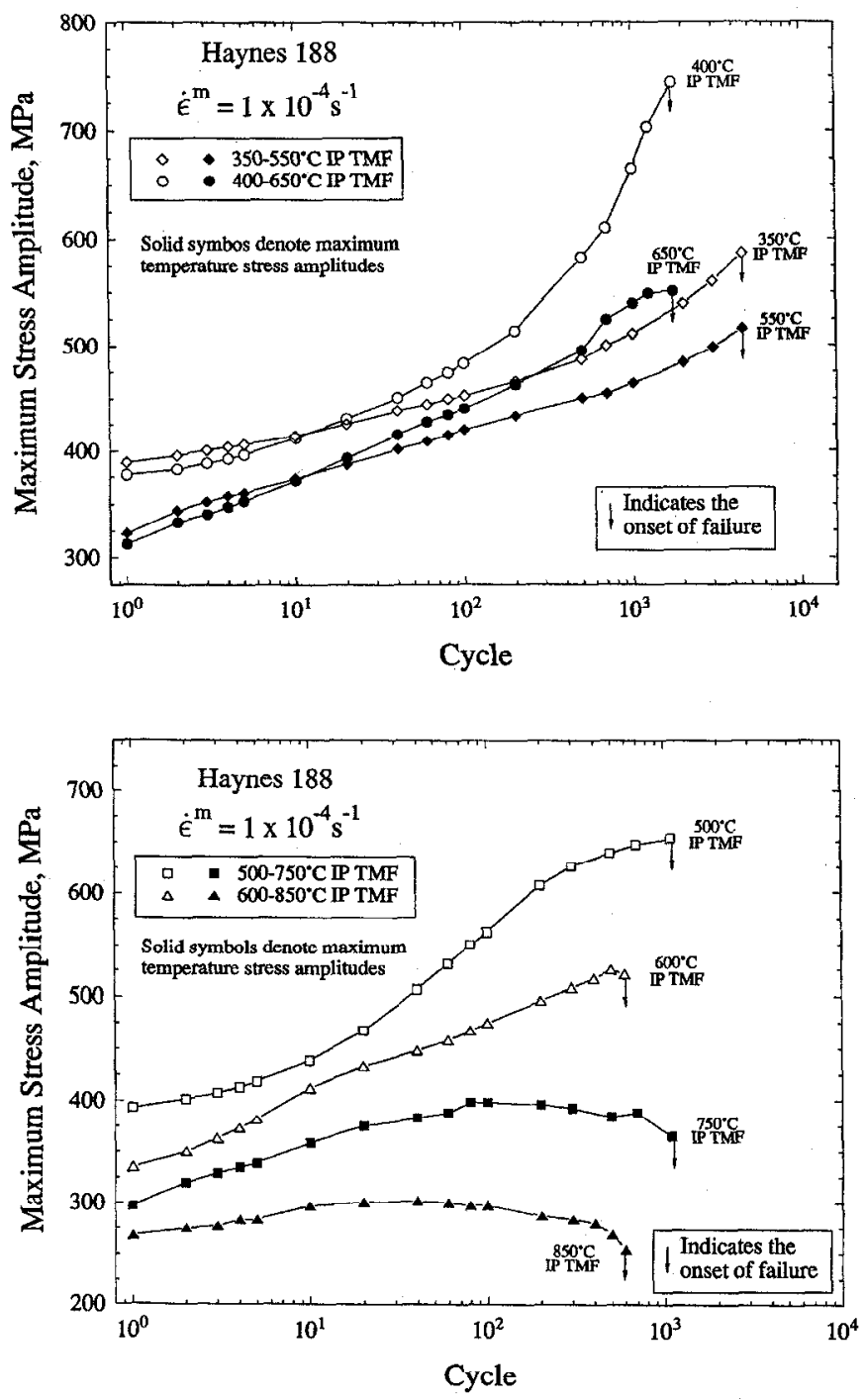

Figure 10: Cyclic maximum stress amplitudes for (a) $\Delta \mathrm{T}: 350$ $550 \& 400-650^{\circ} \mathrm{C}$, and (b) $\Delta \mathrm{T}: 500-750 \& 600-850^{\circ} \mathrm{C}$, IP TMF conditions with $\Delta \varepsilon^{\mathrm{m}}=0.8 \%$ and $\varepsilon^{\mathrm{m}}=10^{-4} \mathrm{~g}^{-1}$.

$850^{\circ} \mathrm{C}$ ) examined. OP TMF conditions were also conducted with similar temperature intervals $(\Delta \mathrm{T})$, but are not shown in Fig. 10 for the sake of clarity. Note that each TMF test must be represented by two curves, one showing the stress amplitude at the maximum temperature (for IP TMF this is tensile) and the other showing the stress amplitude at the minimum temperature (for IP TMF this is compressive). Further, for viewing simplicity, all stress amplitudes are shown as being positive (tensile). In the TMF test with $\Delta \mathrm{T}=350-550^{\circ} \mathrm{C}$, the maximum and minimum temperatures were within and below the DSA range, respectively (for $\varepsilon=10^{-4} \mathrm{~s}^{-1}$ ), while in the $500-750$ and $600-850^{\circ} \mathrm{C}$ tests the maximum and minimum temperatures were above and within the DSA range, respectively. The test with $\Delta \mathrm{T}=400-650^{\circ} \mathrm{C}$ is entirely within the DSA range.

In the isothermal fatigue tests, tensile and compressive stress amplitudes in any given cycle were essentially equal, whereas in the TMF tests, mean stresses developed as a consequence of the dynamic temperature conditions; the cyclic progression of these mean stress values are given in Fig. 11 where additional OP TMF tests are also included. IP TMF tests (such as those 


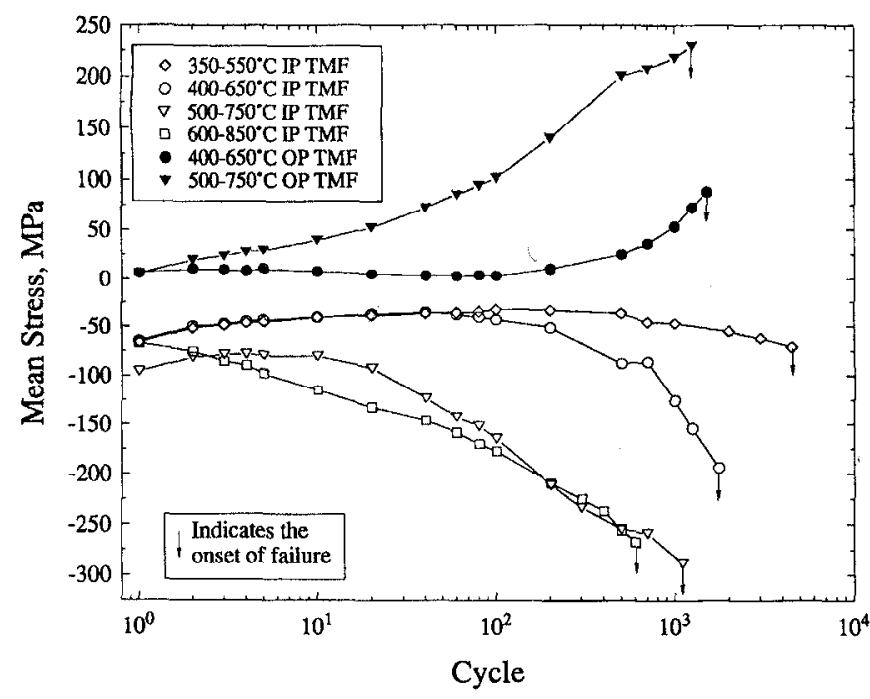

Figure 11: Cyclic mean stresses developed during TMF tests.

shown in Fig. 10), developed a compressive mean stress, that is, the compressive stress amplitudes were higher than the tensile stress amplitudes, whereas, OP TMF conditions led to tensile mean stresses. The mean stress was mild in the $350-550^{\circ} \mathrm{C}$ test; however, the other TMF tests experienced significant mean stresses which generally tended to increase with cycling. The mean stresses developed were particularly large when the maximum temperature of the TMF cycle was above and the minimum temperature was within the DSA range. This result was due to the fact that DSA enhanced hardening was prevalent at one extreme of the cycle and softening due to thermal recovery effects was prevalent at the other extreme. Also note in Fig. 11 that the IP TMF mean stress values were representative of those experienced under OP TMF conditions (for identical $\Delta T$ ) when accounting for the tension/compression difference.

In all the TMF tests, the maximum stresses achieved just prior to the onset of failure at the maximum temperatures of the cycles were almost identical to those attained in corresponding isothermal tests; however, the number of cycles needed to attain the maximum in each of the TMF tests was less than those in the isothermal tests. In contrast, the maximum stresses achieved at the minimum temperature extremes in the TMF tests were not well represented by the isothermal tests performed at corresponding temperatures. This may suggest that the TMF macroscopic behavior is most influenced by the substructural features associated with the peak temperature, as was found with the nickel base superalloy, Hastelloy X $[11,16]$.

In general, the low-temperature peak stresses experienced greater increases in the TMF tests showing significant deviations from the corresponding isothermal tests. This effect was most pronounced in the tests conducted with a temperature interval of $400-650^{\circ} \mathrm{C}$. Results for this $\Delta T$ condition for both IP and OP TMF are presented in Fig. 12 along with data from isothermal fatigue tests conducted at 400 and $650^{\circ} \mathrm{C}$ with $\varepsilon=10^{-4} \mathrm{~s}^{-1}$. As shown here, the maximum hardening rates and magnitudes experienced by the $400^{\circ} \mathrm{C}$ TMF peaks far exceeded those displayed isothermally at $400^{\circ} \mathrm{C}$. This indicates that the TMF stress hardening at $400^{\circ} \mathrm{C}$ could not have been anticipated from the isothermal data. Further, the stress values achieved far exceeded (by 25 to $35 \%$ ) those experienced isothermally at $650^{\circ} \mathrm{C}$. This is a significant result considering that the $650^{\circ} \mathrm{C}$ isothermal values represent the maximum for the entire isothermal data

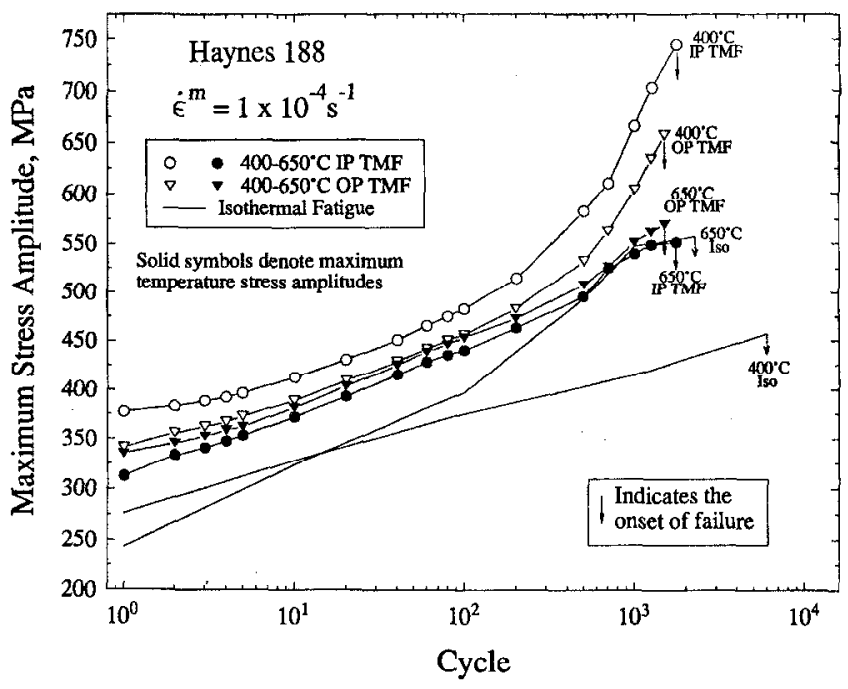

Figure 12: Cyclic maximum stress amplitudes for IP and OP TMF with $\Delta \mathrm{T}=400-650^{\circ} \mathrm{C}$ and corresponding isothermal fatigue tests at the temperature extremes.

base. This isothermally unbounded behavior is clear evidence of thermomechanical path dependence, as the material behavior observed at $400^{\circ} \mathrm{C}$ is profoundly influenced by the deformation substructure developed over the full $\Delta T$. Although the minimum temperature peak stresses in the $500-750^{\circ} \mathrm{C}$ cycles showed the excessive increase due to DSA effects when compared to the isothermal test at $500^{\circ} \mathrm{C}$, the amount of hardening was far less than that obtained in the $400-650^{\circ} \mathrm{C}$ TMF tests, because part of the cycle lied in the range where thermal recovery effects became operative. In the TMF tests with $\Delta \mathrm{T}=600-850^{\circ} \mathrm{C}$, where the main fraction of the cycle involves loading above the DSA range, it is apparent that the thermal recovery effects have become substantial, causing the hardening mechanisms associated with DSA to be less effective at the lower temperature extreme of the cycle.

\section{Summary and Concluding Remarks}

Isothermal and thermomechanical fatigue (TMF) experiments under fully reversed $0.8 \%$ mechanical axial-strain control with strain rate $(\varepsilon)$ values of $10^{-3} \mathrm{~s}^{-1}$ and $10^{-4} \mathrm{~s}^{-1}$ were conducted on Haynes $188^{\mathrm{in}}$ over the temperature range $25-1000^{\circ} \mathrm{C}$. Detailed characterizations of both the macroscopic and microstructural deformation behaviors were conducted.

The fatigue deformation and stress response indicated the operation of dynamic strain aging (DSA) processes, nominally between the temperatures of 300 and $700^{\circ} \mathrm{C}$. DSA was evidenced through a combination of phenomena, including serrated yielding, an inverse dependence of maximum cyclic hardening with $\xi$, and an inverse instantaneous $\varepsilon$ sensitivity. A maximum isothermal cyclic stress amplitude was experienced at $650^{\circ} \mathrm{C}$ for both strain rates examined. At the microstructural level, the occurrence of DSA was found to be associated with pronounced planar slip, generation of stacking faults and relatively high dislocation densities. Stress hardening behaviors exhibited under TMF conditions at the maximum temperature cycle extremes agree closely with those exhibited under isothermal conditions. However, TMF minimum temperature extremes are not accurately predicted from the isothermal data. The TMF deformation results indicate strong thermomechanical path dependence. 
References

1. Haynes Alloy $188^{\mathrm{Tw}}$, (Report-Haynes International, Inc., Kokomo, Indiana, 1991).

2. D.L. Klarstorm and G.Y. Lai, Superalloys 1988, (The Metallurgical Society, 1988) 585-594.

3. G.R. Halford, J.F. Saltsman, and S. Kalluri, "High Temperature Fatigue Behavior of Haynes 188," (Presented at Advanced Earth-to-Orbit Propulsion Technology Conference, MSFC, Huntsville, AL, May 10-13, 1988; Report NASA CP-3012) 1(1988), 497-507.

4. G.R. Halford, et al., "Thermomechanical and Bithermal Fatigue Behavior of Cast B1900+Hf and Wrought Haynes 188," ASTM STP 1122, (1992), 120-142.

5. S. Kalluri and G.R. Halford, "Damage Mechanisms in Bithermal and Thermomechanical Fatigue of Haynes 188," ASTM STP 1186, (1993), 126-143.

6. V.M. Radhakrishnan, S. Kalluri, and G.R. Halford, "An Analysis of Isothermal, Bithermal, and Thermomechanical Fatigue Data of Haynes 188 and B1900+Hf by Energy Considerations," (Report NASA TM-106359, Sept., 1993).

7. D.A. Jabolonski, J.V. Barisella, and R.M. Pelloux, Metall. Trans. A 8A(1977), 1893-1900.

8. P.J. Bonacuse and S. Kalluri, "Cyclic Axial-Torgional Deformation Behavior of a Cobalt-Base Superalloy," (Report NASA TM-106372, 1992).

9. K. Bhanu Sankara Rao, et al., "A Critical Assessment of the Mechanistic Aspects in Haynes 188. During Low Cycle Fatigue in the Range 25 to $1000^{\circ} \mathrm{C}$, Metall. Trans. A accepted for publication.

10. K. Bhanu Sankara Rao, M.G. Castelli and J.R. Ellis, "On the Low Cycle Fatigue Deformation of Haynes 188 Superalloy in the Dynamic Strain Aging Regime," Script Met. 33(1)(1995).

11. M.G. Castelli, R.V. Miner and D.N. Robinson, "Thermomechanical Deformation Behavior of a Dynamic Strain Aging Alloy," ASTM STP 1186, (1993), 106-125.

12. R. Zauter, F. Petry, H.J. Christ and H. Mughrabi, "Thermomechanical Fatigue of the Austenitic Stainless Steel AISI 304L," ASTM STP 1186, (1993), 70-90.

13. K. Bhanu Sankara Rao, et al., High Temp. Mater. and Processes, 7(1986), 171-177.

14. V. S. Sreenivasan, et al., Int. J. Fat. 13(1991), 471-478.

15. K. Bhanu Sankara Rao, "Influence of Metallurgical Variables on Low Cycle Fatigue Behavior of Type 304 Stainless Steel," (Ph.D. Thesis, IGCAR-Kalpakkam and University of Madras, India, Jan. 1989).

16. R.V. Miner and M.G. Castelli, "Hardening Mechanisms in a Dynamic Strain Aging Alloy, Hastelloy X, During Isothermal and Thermomechanical Cyclic Deformation," Metall. Trans. A 23A(1992), 551-561.
17. R.E. Reed Hill, Rev. High. Temp. Mater., 2 1974), 217-242.

18. K. Bhanu Sankara Rao, et al. Metals, Materials and Processes, 2(1990), 17-36. 